\title{
Experimental Study and Application Analysis of Chemical Curing Soil
}

\author{
Mao Lin, Yanfeng Tian, Xiaoqing Yu and Gongli $\mathrm{Hu}$ \\ Gulou District of Xuzhou City, West Club Street, No. 86, Jiangsu, China
}

\begin{abstract}
Based on the curing mechanism of soil stabilizer, use 'Toogood'soil stabilizer to solidify soil and study the curing effect. To obtain the best curing agent stabilized soil mixing ratio, this paper analyzed the soil particles, the compaction test and unconfined compressive strength test. Mix in the best on basis of obtained maintenance curing soil conditions on the effects of strength. Through analyzing the test results of research, that the soil curing agent can be used as a new material for application in military engineering repair scrambling, has good military and economic effect.
\end{abstract}

Keywords-soil curing agent; unconfined compressive strength; compaction test

Soil curing agent is added in the soil admixture, added to the soil with the soil to a series of physical - chemical reaction, the soil into a solid and lasting solidified soil, improve soil physical - mechanical properties[1], improve soil engineering properties, Reducing soil water sensitivity and improving soil water stability. The material used to solidify the soil was originally lime, fly ash, cement, etc. or a combination of several of them, and later developed into the current mass can be mass production of soil curing agent. China's soil curing agent for the study is still in its infancy, but also achieved some results, many of our own soil curing agent from the laboratory applied to the engineering practice[2]. In this paper, chemical curing agent for the research object, after curing the soil strength analysis, with a view to the airport pavement surface treatment and wartime repair rush to provide reference[3].

In practice, most countries and regions mostly use unconfined compressive strength as an indicator of the strength of solidified soil. Therefore, the unconfined compressive strength of the cured soil is studied in this paper.

\section{TeSt Materials AND Methods}

\section{A. Soil Samples}

In this experiment, soil samples were taken from Xuzhou area. Test soil physical properties indicators in Table I.

TABLE I. TABLE TYPE STYLES PHYSICAL PROPERTIES OF SOIL SAMPLES TESTED

\begin{tabular}{|c|c|c|c|}
\hline Soil samples & 1 & 2 & 3 \\
\hline Apparent density of soil/g.cm-3 & 1.65 & 2.01 & 2.11 \\
\hline Water content/\% & 16.22 & 22.58 & 15.09 \\
\hline
\end{tabular}

\section{B. Soil Curing.}

The chemical curing agent chosen in this experiment is "Gusujing" brand liquidSoil curing agent, the soil curing agent is a non-toxic, harmless, non-pollutingEnvironmental protection high cluster organic solution, is the eighth generation of polymer soil curing agent, itsThe main components are ionic compounds, water, initiator, active agent, solution wasBlack, orange, blue, purple, the density is generally $1.25 \sim 1.75 \mathrm{~g} / \mathrm{cm} 3$, Plasticity index IP greater than 7 , particle size component ps greater than $18, \mathrm{PH}$ value greater than 10 ,Boiling point greater than $100{ }^{\circ} \mathrm{C}$, is a non-toxic, harmless,non-polluting, non-volatile,Non-flammable environmentally friendly products, in the course of the use of no special protectionMeasures.

\section{EASE OF USE EXPERIMENT METHOD}

There are no specific test procedures for solidified soils used as base materials. Therefore, the indoor test part of this study is referred to as the "Highway Engineering Inorganic Binder Stabilized Materials Testing Procedures" (JTJ057-2009), the "Highway Soil Test Regulations" (JTGE40-2007) and "Highway asphalt pavement design specifications" (JTGD502006) and so on[4] [5].

Compaction test using the standard light compaction test, the determination of boundary moisture content using photoelectric liquid-plastic limit joint measuring instrument, dry density measurement using alcohol combustion method, unconfined compressive strength using strain-controlled unconfined pressure gauge. The specimens were cured to the specified age under the standard curing conditions of temperature $(20 \pm 2){ }^{\circ} \mathrm{C}$ and relative humidity of more than $95 \%$ using a cylinder with diameter $\times$ height of $50 \mathrm{~mm} \times 50 \mathrm{~mm}$ respectively.

As the soil curing agent is characterized by the largest can be a relatively small dose, increase the strength of soil. Test program for the treatment of soil using three methods, one program is for different water content of the soil after solidification for compaction; the second is to compaction after unconfined compressive strength test; the third is after curing The curing properties of the cured soils were analyzed in detail, and the accumulated experimental data were used for the later practical projects. 


\section{A. Compaction Test}

A compaction test is a method of increasing soil density by hammering. Soil in a certain compaction effect, if the water content is different, the resulting density is different, can make the soil to achieve the maximum density required water content, become the optimal moisture content, the corresponding dry density, said the maximum dry density. Compaction tests were carried out using a light compaction apparatus (hammer weight $2500 \mathrm{~g}$, drop distance $300 \mathrm{~mm}$, volume $1000 \mathrm{~cm}^{3}$ ).

The dry density as the vertical axis, the water content of the abscissa, draw dry density and water content curve, the coordinates of the peak points on the curve were the maximum soil density and optimal water content, if not a complete curve, should be Fill point test.

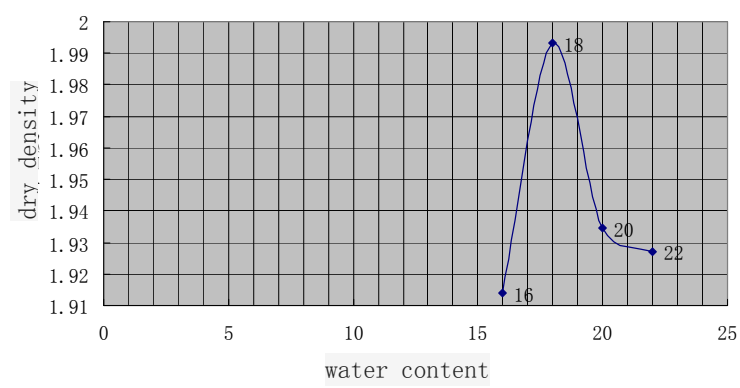

FIGURE I. DRY DENSITY AND WATER CONTENT CURVE

As can be seen from Figure I, when the mixture moisture content of $18 \%$, then the corresponding mixture of the maximum density. So the best water content of $18 \%$, the maximum dry density of $1.992 \mathrm{~g} / \mathrm{cm} 3$. Curing agent and water according to the water content ratio of $18 \%$. After the demolding of the test pieces obtained after the compaction test, the samples were put in $20 \pm 2{ }^{\circ} \mathrm{C}$ and relative humidity $\geq 95 \%$ in the oven, 6 days of conservation, and then 7 days into about $25^{\circ}$ of water conservation, and then no lateral compressive strength test.

\section{B. Unconfined compressive strength test}

The unconfined compressive strength of the test specimens was measured to obtain the mixing ratio in accordance with the test requirements. And then the different ages of the specimens were measured, and then get the best test results.

(a) Determination of the best mix

$(5 \%, 10 \%, 15 \%, 20 \%$, all dry soil percentage) of the curing agent for unconfined compressive strength test. The results are as follows:

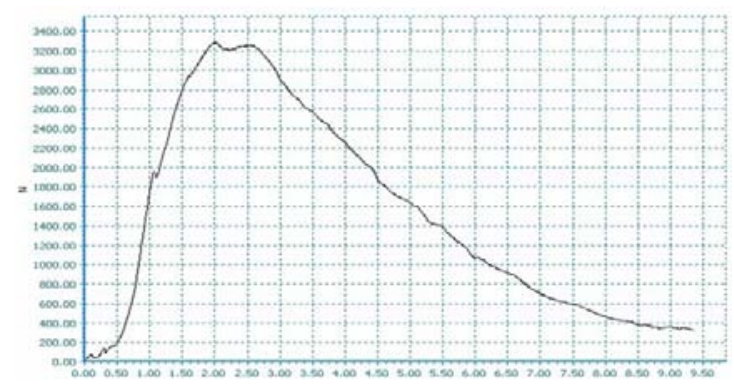

FIGURE II. TEST FORCE - DISPLACEMENT CURVE PRIME SOIL $+5 \%$ HARDENER

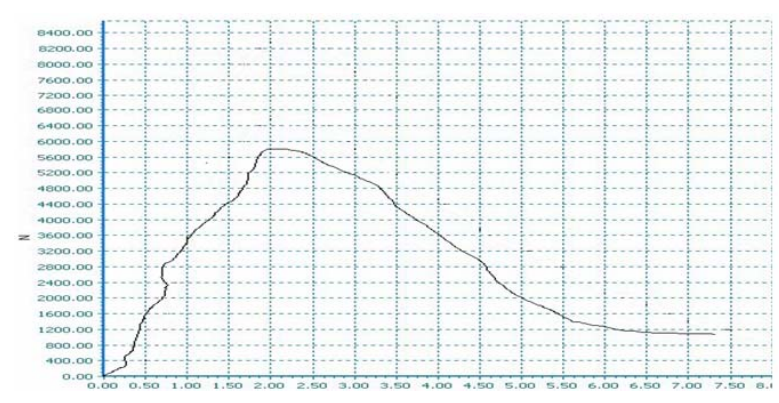

FIGURE III. TEST FORCE - DISPLACEMENT CURVE PRIME SOIL $+10 \%$ HARDENER

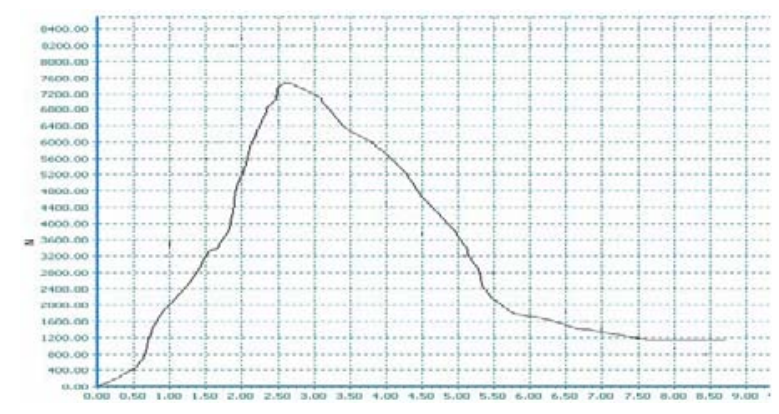

FIGURE IV. TEST FORCE - DISPLACEMENT CURVE PRIME SOIL+15\%HARDENER

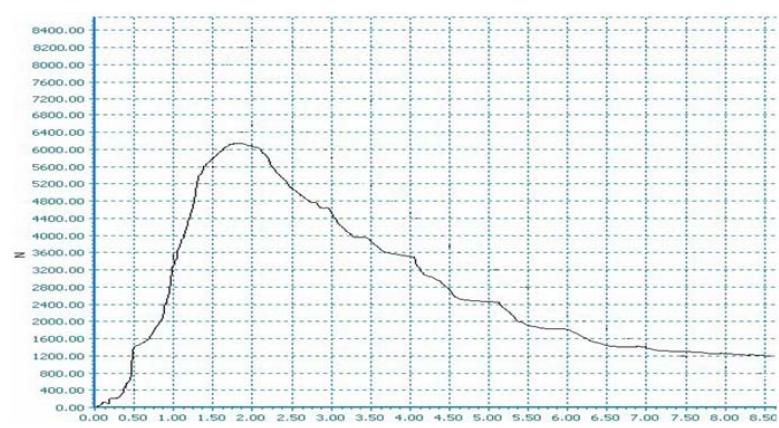

FIGURE V. TEST FORCE - DISPLACEMENT CURVE PRIME SOIL $+20 \%$ HARDENER

Figure II, Figure II, Figure IV, Figure V, respectively, for the incorporation of different proportions of the curing agent curing block stress-strain curve, after finishing the Table II: 
TABLE II. UNCONFINED COMPRESSIVE STRENGTH TEST RESULTS

\begin{tabular}{|l|c|}
\hline \multirow{2}{*}{ Sample type } & Unconfined compressive strength \\
\cline { 2 - 2 } & average value/MPa \\
\hline Prime soil & 0.28 \\
\hline Prime soil $+5 \%$ Hardener & 0.65 \\
\hline Prime soil $+10 \%$ Hardener & 1.17 \\
\hline Prime soil $+15 \%$ Hardener & 1.55 \\
\hline Prime soil $+20 \%$ Hardener & 1.23 \\
\hline
\end{tabular}

As can be seen from Table II, under the same conditions to add several different proportions of curing agent, found that when the curing agent content of $15 \%$, the specimen unconfined compressive strength showed the best, which can be inferred When the soil by adding about $15 \%$ curing agent when the curing effect is the best.

\section{(b)Determine the appropriate curing time}

In order to further optimize the test results, the unconfined compressive strength of soil with $15 \%$ hardening agent at different ages was tested in order to obtain the best experimental results. The test results of unconfined compressive strength of specimens immersed in different ages are as follows:

\section{TABLE III. RESULTS OF UNCONFINED COMPRESSIVE STRENGTH TESTS OF IMMERGED SOILS AT DIFFERENT AGES}

\begin{tabular}{|l|l|l|c|c|}
\hline \multirow{2}{*}{$\begin{array}{c}\text { Sample } \\
\text { type }\end{array}$} & Curing conditions & \multirow{2}{*}{$\begin{array}{c}\text { Age } \\
\text { /d }\end{array}$} & \multicolumn{2}{|c|}{$\begin{array}{c}\text { Unconfined compressive } \\
\text { strength }\end{array}$} \\
\cline { 4 - 5 } & & $\begin{array}{c}\text { average } \\
\text { value/MPa }\end{array}$ & $\begin{array}{c}\text { growth } \\
\text { rate/\% }\end{array}$ \\
\hline \multirow{2}{*}{$\begin{array}{l}\text { Primesoil+ } \\
5 \% \text { Harden } \\
\text { er }\end{array}$} & $\begin{array}{l}\text { Standard curing 6d, } \\
\text { water 1d }\end{array}$ & 7 & 1.55 & - \\
\cline { 2 - 5 } & $\begin{array}{l}\text { Standard curing 6d, } \\
\text { water 8d }\end{array}$ & 14 & 1.93 & 24.516 \\
\cline { 2 - 5 } & $\begin{array}{l}\text { Standard curing 6d, } \\
\text { water 22d }\end{array}$ & 28 & 2.36 & 22.279 \\
\hline \multicolumn{2}{|l|}{ Note: The material content is the mass ratio } \\
\hline
\end{tabular}

It can be seen from Table III that the unconfined compressive strength of the cured soil increases with the increase of the age under immersion conditions.

\section{SUMMARY}

Through the experimental study on the solidified soil of the chemical curing agent, we can draw the following conclusions:

(1) The addition of the chemical curing agent to the unconfined compressive strength of soil-based significantly improved, according to the need to obtain the same compressive strength, and other solidified soil-based materials, construction costs compared to give the project to provide choice ;

(2) The unconfined compressive strength of the soil stabilized by the chemical curing agent is greatly affected by the dosage and age of the curing agent, and the curing agent formula can be adjusted according to the engineering requirements and construction technology.

(3) The early strength of the soil curing agent, can speed up the construction schedule;
(4) In view of the above characteristics, the soil hardening agent can be used as a new material in the military engineering repair and construction in the application, such as for the flight field, you need to soil curing agent solidified soil durability and Permeability.

\section{REFERENCES}

[1] FAN Heng-hui WU Pu-te GAO Jian-en LOU Zong-ke. Microstructure Characteristics of Soil Stabilized with Cement-based Soil Stabilizer. JOURNAL OF BUILDING MATERIALS. 2010.13(5)

[2] BAI Chun-zhen XU Yan WU Ze-feng LU Xin LI Di.Research and Development of Soil Curing Agent and Stabilized Soil Pavement Base.Northern Communications. 2014.(8)

[3] LIU Shi-jiao FAN Heng-hui SHI Xiang HE Zhi-qiang Durability of stabilized soil by BCS. Journal of Northwest A\&F University(Natural Science Edition). 2014.42(12)

[4] SUN Jiaying GU Xin Engineering Properties of the New Non-clinker Incorporating Soda Residue Solidified Soil. Journal of Building Materials 2014.17(6)

[5] YAN Hui FAM Xin-ku GAO Wei Test of Liquid and Powder Stabilizer Applicated in Road.Construction \& Design for Project.2016.(8) 